\title{
Evidence for a role of oxygen derived free radicals in the pathogenesis of caerulein induced acute pancreatitis in rats
}

\author{
J WISNER, D GREEN, L FERRELL, AND I RENNER
}

From the Department of Medicine, Section of Gastroenterology, University of Southern California School of Medicine, Los Angeles, California and Department of Pathology, University of California School of Medicine, San Francisco, California, USA

SUMmary The effects of a polyethylene glycol linked oxygen free radical scavenger enzyme, superoxide dismutase (PEG:SOD) on caerulein induced acute pancreatitis (AP) in rats were examined. Pancreas weights and serum amylase concentrations in rats given a three hour continuous intravenous infusion of caerulein $(7 \cdot 5 \mu \mathrm{g} / \mathrm{kg} / \mathrm{h}, \mathrm{n}=18)$ for induction of $\mathrm{AP}$ followed by a three hour infusion of normal saline were significantly raised by approximately $25 \%(p<0.005)$ and $750 \%$ $(p<0 \cdot 001)$, respectively, compared with values obtained in control rats $(n=7)$ infused for six hours with normal saline alone. A single intraperitoneal injection of either $1 \times 10^{4} \mathrm{U} / \mathrm{kg}(\mathrm{n}=6), 2 \times 10^{4} \mathrm{U} / \mathrm{kg}$ $(n=5)$, or $4 \times 10^{4} \mathrm{U} / \mathrm{kg}(\mathrm{n}=5)$ of PEG:SOD immediately before caerulein infusion did not significantly alter pancreas weights, serum amylase content, or pancreatic histopathology compared with rats given caerulein alone. By contrast, a single intravenous bolus injection of $4 \times 10^{4} \mathrm{U} / \mathrm{kg}(\mathrm{n}=9)$ of PEG:SOD before caerulein treatment significantly reduced serum amylase content by approximately $25 \%(\mathrm{p}<0.05)$ and a continuous six hour intravenous infusion of $4 \times 10^{4} \mathrm{U} / \mathrm{kg} / \mathrm{h}$ of PEG:SOD $(n=5)$ produced significant reductions of approximately $25 \%(p<0 \cdot 001), 35 \%(p<0 \cdot 05)$, and $50 \%$ $(\mathbf{p}<0.01)$ in pancreas weights, serum amylase concentrations, and acinar cell vacuolisation $(\mathbf{p}<\mathbf{0 \cdot 0 1})$, respectively, compared with values in rats given caerulein alone. In studies using bovine serum albumin linked to polyethylene glycol and infused for six hours at protein concentrations identical to high dose PEG:SOD $(n=6)$, no beneficial effects against caerulein induced AP were observed. These data suggest that (a) oxygen derived free radicals are involved in the early pathogenesis of caerulein induced $A P$ in rats, and (b) the greatly extended circulating half life of polyethylene PEG:SOD (>35 hours in rats compared with less than six minutes for native superoxide dismutase) may make this compound more suitable than native superoxide dismutase as a potential therapeutic agent in AP.

Major aetiological factors associated with development of acute pancreatitis (AP) are biliary tract disease and chronic alcoholism. ${ }^{12}$ The specific cellular mechanism(s) resulting in AP are not clear. There is, however, general agreement (derived from clinical studies and animal models of the disease) that inappropriate intraparenchymal activation of

Address for correspondence: Dr James R Wisner, Jr, Department of Medicine, Section of Gastroenterology, USC School of Medicine, HMR 902, 2025 Zonal Avenue, Los Angeles, California 90033, USA.

Received for publication 1 June 1988. pancreatic enzymes occurs in AP - for example, trypsin, chymotrypsin, elastase, phospholipase $\mathrm{A}_{2}$ ) and leads to autodigestion of the gland. ${ }^{2-5}$

Extensive experimental evidence has implicated oxygen derived free radicals - for example, superoxide anion, hydroxyl radical, as well as hydrogen peroxide generated in vivo as important mediators in the pathogenesis of numerous forms of tissue injury and a potential role for free radicals in the early pathogenesis of AP has recently emerged from work by Sanfey $e t a^{910}$ using an $e x$ vivo, perfused canine 
pancreas model of the disease. In this latter work, perfusion of the dog pancreas with the oxygen derived free radical scavenging enzymes superoxide dismutase (SOD) and catalase (CAT) before induction of AP by either arterial perfusion of a free fatty acid, a period of total arterial ischaemia, or partial pancreatic duct obstruction coupled with secretin stimulation significantly protected against development of AP. ${ }^{910}$ More recently, however, in vivo studies in mice with either caerulein (CR)-induced AP or a lethal, haemorrhagic AP induced by feeding a choline deficient, ethionine supplemented (CDE) diet have yielded somewhat contradictory results on the potential involvement of oxygen derived free radicals in AP. Thus, it has been reported in mice with diet induced pancreatitis that exogenously administered CAT fails to reduce peripancreatic oedema, hyperamylaesaemia, or mortality rates ${ }^{11}$ and that exogenously administered SOD fails to alter pancreatic oedema or hyperamylaesaemia in mice with CR induced AP.12 Others, however, have reported that SOD exerts beneficial effects on CR induced AP in rats. ${ }^{13}$

In this study we have re-examined whether exogenous SOD can protect the rat pancreas from development of AP in vivo. We chose to induce AP by a continuous intravenous (iv) infusion of $C R$ in supramaximal doses as this model of the disease consistently produces a florid AP characterised by intense interstitial oedema, acinar cell vacuolisation, and hyperamylaesaemia as early as $\mathbf{3 0}$ minutes after the beginning of CR infusion ${ }^{4514-16}$ and has been used extensively for the study of AP and evaluation of potential therapeutic agents in this disease..$^{451423}$ Additionally, we chose to examine the effects of a polyethylene glycol (PEG):SOD adduct rather than the native enzyme because the derivatised enzyme has a greatly extended serum half life $\left(t_{1 / 2}=\right.$ approximately 15 hours in mice and 35 hours in rats compared with a $t_{1 / 2}$ of native SOD of approximately six minutes in rats) and a greater anti-inflammatory potency in rats compared with native SOD. ${ }^{2+27}$

\section{Methods}

ANIMALS AND SURGICAL PROCEDURES Adult male Wistar rats (180-220 g body wt) were purchased from Simonsen Laboratories, Gilroy, CA and were deprived of food but not water for 18 hours before the experiment.

Animals were anaesthetised by a single intraperitoneal (ip) injection of sodium pentobarbital (30 $\mathrm{mg} / \mathrm{kg}$ ) and the left external jugular vein was catheterised with PE-50 polyethylene tubing as previously described. ${ }^{21}$ The jugular cannula was exteriorised at the nape of the neck through a subcutaneous tunnel and after regaining consciousness, rats were transferred to individual cages containing plastic blocks to restrict lateral movement. In experiments in which animals received an iv bolus injection or an iv infusion of PEG:SOD as well as $\mathrm{CR}$, bilateral jugular vein cannulae were used in order to avoid mixing of the test substances. Immediately before the experiments a basal ( 0 time) tail vein blood sample $(0.2 \mathrm{ml})$ was obtained. Continuous iv infusions of test substances were conducted using a Harvard Syringe Infusion Pump (Model 2681) at a flow rate of $0.5 \mathrm{ml} / \mathrm{h}$.

\section{CHEMICALS}

Synthetic CR was purchased from Sigma Chemical Co, St Louis, MO, USA. Highly purified bovine erythrocyte-derived SOD linked to PEG (2-omethoxypolyethylene glycol-4,6-dichlorotriazine; $2900 \mathrm{U} / \mathrm{mg}$ protein, Lot No 86D-2611REB2) and PEG-linked bovine serum albumin (PEG:BSA; 5.2 $\mathrm{mg}$ protein/ml, Lot No J8701003) were gifts from Enzon Inc, South Plainfield, NJ). One unit of PEG:SOD enzyme activity used in the present study is defined as the amount of PEG:SOD required to augment peroxidation of dianisidine by a factor of $10^{-6} \mathrm{~A} 460 / \mathrm{min} .^{24}$ All substances were dissolved in sterile normal saline immediately before use.

\section{EXPERIMENTAL DESIGN}

Animals were randomly divided into eight groups and subjected to the following treatment regimens: group 1 (controls, $n=7$ ): infused iv for six hours with normal saline; group $2(n=18)$ : infused iv for three hours with CR $(7.5 \mu \mathrm{g} / \mathrm{kg} / \mathrm{h})$ for induction of AP followed by a three hour infusion of normal saline; group $3(n=6)$ : injected ip $\times 1$ at $t=0$ with PEG:SOD $(10000 \mathrm{U} / \mathrm{kg})$, iv infused for three hours with CR (7.5 $\mu \mathrm{g} / \mathrm{kg} / \mathrm{h}$ ), and subsequently iv infused for three hours with normal saline; group $4(n=5)$ : injected ip $\times 1$ at $\mathrm{t}=0$ with PEG:SOD $(20000 \mathrm{U} / \mathrm{kg})$ and iv infused for three hours with CR $(7.5 \mu \mathrm{g} / \mathrm{kg} / \mathrm{h})$ followed by a three hour infusion of normal saline; group $5(n=5)$ : injected ip $\times 1$ at $\mathrm{t}=0$ with PEG:SOD $(40000 \mathrm{U} / \mathrm{kg}$ and iv infused for three hours with CR $(7.5 \mu \mathrm{g} / \mathrm{kg} / \mathrm{h})$ followed by a three hour infusion of normal saline; group $6(n=9)$ : injected iv $\times 1$ at $t=0$ with PEG:SOD $(40000 \mathrm{U} / \mathrm{kg})$ and iv infused for three hours with CR $(7.5 \mu \mathrm{g} / \mathrm{kg} / \mathrm{h})$ followed by a three hour infusion of normal saline; group $7(n=5)$ : infused iv for three hours with a combination of PEG:SOD $(40000 \mathrm{U} / \mathrm{kg}$ ) h) and CR $(7.5 \mu \mathrm{g} / \mathrm{kg} / \mathrm{h})$ followed by a further three hour continuous iv infusion with PEG:SOD $(40000$ $\mathrm{U} / \mathrm{kg} / \mathrm{h})$ alone; group $8(\mathrm{n}=8)$ : infused iv for three hours with a combination of PEG:BSA $(13.8 \mathrm{mg}$ protein $/ \mathrm{kg} / \mathrm{h})$ and CR $(7.5 \mu \mathrm{g} / \mathrm{kg} / \mathrm{h})$ followed by a 
Table 1 Influence of PEG:SOD on pancreas weights and serum amylase concentrations in rats with $C R$ induced $A P$

\begin{tabular}{|c|c|c|c|}
\hline \multirow[b]{2}{*}{ Treatment groups } & \multirow[b]{2}{*}{ Pancreas wt $(\mathrm{g} / 100 \mathrm{~g}$ body $w t)$} & \multicolumn{2}{|c|}{ Serum amylase $(I U / m l)$} \\
\hline & & Basal & 6hours \\
\hline Controls $(\mathrm{n}=7)^{*}$ & $0 \cdot 582(0 \cdot 032)$ & $7 \cdot 26(0 \cdot 41)$ & $7 \cdot 45(0 \cdot 68)$ \\
\hline $\mathrm{CR}(\mathrm{n}=18)+(7.5 \mu \mathrm{g} / \mathrm{kg} / \mathrm{h} \times$ three hours $)$ & $0.734(0 .(25) 9$ & $7.79(0 \cdot 67)$ & $63 \cdot 3(2 \cdot 69)^{* *}$ \\
\hline $\mathrm{CR}+\mathrm{PEG}: \mathrm{SOD}(\mathrm{n}=6)\left(10 \times 10^{\prime} \mu / \mathrm{kg}\right.$ ip bolus $)$ & $0.779(0.049) \|$ & $8 \cdot 10(0 \cdot 81)$ & $63 \cdot 6(4 \cdot 93)^{* *}$ \\
\hline CR + PEG:SOD $(n=5)\left(20 \times 10^{3} \mu / \mathrm{kg}\right.$ ip bolus $)$ & $0 \cdot 760(0 \cdot(043) \|$ & $7 \cdot 50(0 \cdot 50)$ & $64 \cdot 0(2 \cdot 75)^{* *}$ \\
\hline CR + PEG:SOD $(n=5)\left(40 \times 10^{3} \mu / \mathrm{kg}\right.$ ip bolus $)$ & $0.768(0.037) \pi$ & $6 \cdot 90(0 \cdot 24)$ & $65 \cdot 1(7 \cdot 53)^{* *}$ \\
\hline $\mathrm{CR}+\mathrm{PEG}: \mathrm{SOD}(\mathrm{n}=9)\left(40 \times 10^{3} \mu / \mathrm{kg}\right.$ iv bolus $)$ & $0.768(0 \cdot 067) \S$ & $6 \cdot 50(0 \cdot 29)$ & $49 \cdot 0(5.99)^{* *+\dagger}$ \\
\hline CR+PEG:SOD $(n=5)\left(40 \times 10^{\prime} / / \mathrm{kg} / \mathrm{h} \times\right.$ six hours $)$ & $0.557(0.044) \ddagger \ddagger$ & $6.55(0.98)$ & $41 \cdot 3(7 \cdot 20)^{* *+\dagger}$ \\
\hline $\mathrm{CR}+$ PEG:BSA $(\mathrm{n}=6) \ddagger(13 \cdot 8) \mathrm{mg}$ protein $/ \mathrm{kg} / \mathrm{h} \times$ six hours $)$ & $0.729(0 \cdot 030) \uparrow$ & $7 \cdot 62(0 \cdot 59)$ & $65 \cdot 4(3 \cdot 11)^{* *}$ \\
\hline
\end{tabular}

*Control rats were iv infused for six hours with normal saline: †All CR infusions were iv at a dose of $7 \cdot 5 \mu \mathrm{g} / \mathrm{kg} / \mathrm{h} \times$ three hours followed by a three hour infusion of normal saline; $¥$ The PEG:BSA concentration infused was equivalent to the amount of protein $/ \mathrm{kg} / \mathrm{h}$ of PEG:SOD infused in rats for six hours. All bolus ip or iv injections of PEG:SOD were given immediately before CR infusions. $\S . \|, \uparrow .{ }^{* *}=p<0 \cdot() 5$, $\mathrm{p}<0 \cdot 01, \mathrm{p}<0 \cdot(005, \mathrm{p}<0 \cdot 001$, respectively, compared with untreated control rats. $\dagger+, \ddagger \ddagger=\mathrm{p}<0 \cdot 05, \mathrm{p}<0 \cdot 01$, respectively, when compared with values obtained in rats treated with CR alone. Results are mean (SD).

further three hour continuous iv infusion with PEG:BSA (13.8 $\mathrm{mg}$ protein $/ \mathrm{kg} / \mathrm{h})$ alone.

\section{AUTOPSY, SAMPLE COLLECTION, AND ASSAY PROCEDURES}

At $t=$ six hours after the beginning of the experiments rats were anaesthetised by an ip injection of sodium pentobarbital $(30 \mathrm{mg} / \mathrm{kg})$ and the pancreas was excised and weighed. Animals were subsequently killed by abdominal aortic exsanguination.

Basal (0 time) and terminal (six hour) serum samples were analysed for amylase concentrations using the Phadebas Test ${ }^{21}$ and portions of pancreas were fixed and processed for light microscopy as previously described, ${ }^{21}$ with the exception that the embedding medium was 2-hydroxyethyl methacrylate (Sorvall, Dupont Co, Newtown, Conn, USA).
STATISTICAL ANALYSIS

Statistical analyses of pancreas weights and biochemical data were accomplished using Student's two-tailed $t$ test for independent means. ${ }^{.8}$ For more complex, multiple intercomparisons of data, analysis of variance (ANOVA) and Duncan's new multiple range test were used. ${ }^{29}$ In all instances $p$ values of $<0.05$ were considered to be statistically significant.

Pancreas histology specimens were evaluated in a blind coded fashion by the participating pathologist (LF) who was unaware of the study design or substances tested. Details of the histological grading system have been published previously." 2.3 Histological data were evaluated using the Wilcoxon's rank-sum test ${ }^{28}$ as previously described ${ }^{23}$ and a $p$ value of $<0.01$ between groups was considered to be statistically significant.

Table 2 Influence of PEG:SOD on pancreas histology in rats with CR induced $A P$

\begin{tabular}{|c|c|c|c|}
\hline \multirow[b]{2}{*}{ Treatment groups } & \multicolumn{3}{|c|}{ Pancreas histology* } \\
\hline & Vacuolisation & Necrosis & Inflammation \\
\hline Controls $(n=7)$ & 0) & () & 0 \\
\hline $\mathrm{CR}(\mathrm{n}=19)(7.5 \mu / \mathrm{kg} / \mathrm{h} \times$ three hours $)$ & $2-3 \dagger$ & $+1-$ & $+1-$ \\
\hline CR+PEG:SOD $(n=6)\left(10 \times 10^{2} \mu / \mathrm{kg}\right.$ ip bolus $)$ & $2-3+$ & $+1-$ & $+1-$ \\
\hline $\mathrm{CR}+\mathrm{PEG}: \mathrm{SOD}(\mathrm{n}=5)\left(20 \times 10^{2} \mu / \mathrm{kg}\right.$ ip bolus $)$ & $2-3+$ & $+1-$ & $+1-$ \\
\hline $\mathrm{CR}+\mathrm{PEG}: \mathrm{SOD}(\mathrm{n}=5)\left(40 \times 10^{3} \mu / \mathrm{kg}\right.$ ip bolus $)$ & $2-3+$ & $+1-$ & $+1-$ \\
\hline$C R+P E G: S O D(n=9)\left(40 \times 10^{2} \mu / \mathrm{kg}\right.$ iv bolus $)$ & $2-3 \dagger$ & $+1-$ & $+1-$ \\
\hline CR+PEG:SOD $(n=5)\left(40 \times 10^{i} \mu / \mathrm{kg} / \mathrm{h} \times\right.$ six hours $)$ & $1-2 \ddagger \S$ & $+1-$ & $+1-$ \\
\hline CR+PEG:BSA $(\mathrm{n}=6)(13.8 \mathrm{mg}$ protein $/ \mathrm{kg} / \mathrm{h} \times$ six hours $)$ & $2-3 \dagger$ & $+1-$ & $+1-$ \\
\hline
\end{tabular}

Animals were treated according to the protocols described in the legend for Table $1 .{ }^{*}=$ Values for pancreas histology represent the range observed for all animals in each category. Acinar cell vacuolisation, necrosis, and inflammation in the pancreas of all animals was quantified as the approximate percentage of cells involved with scores of 0 indicating absent $+/-=$ minimal or absent, $1=5-15 \%, 2=15-35 \%, 3=35-$

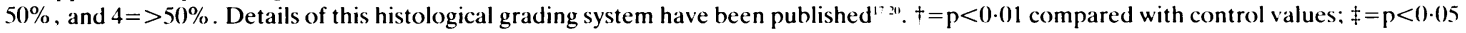
compared with control values; $\$=p<0 .(01$ compared with values in rats iv infused with CR alone. 


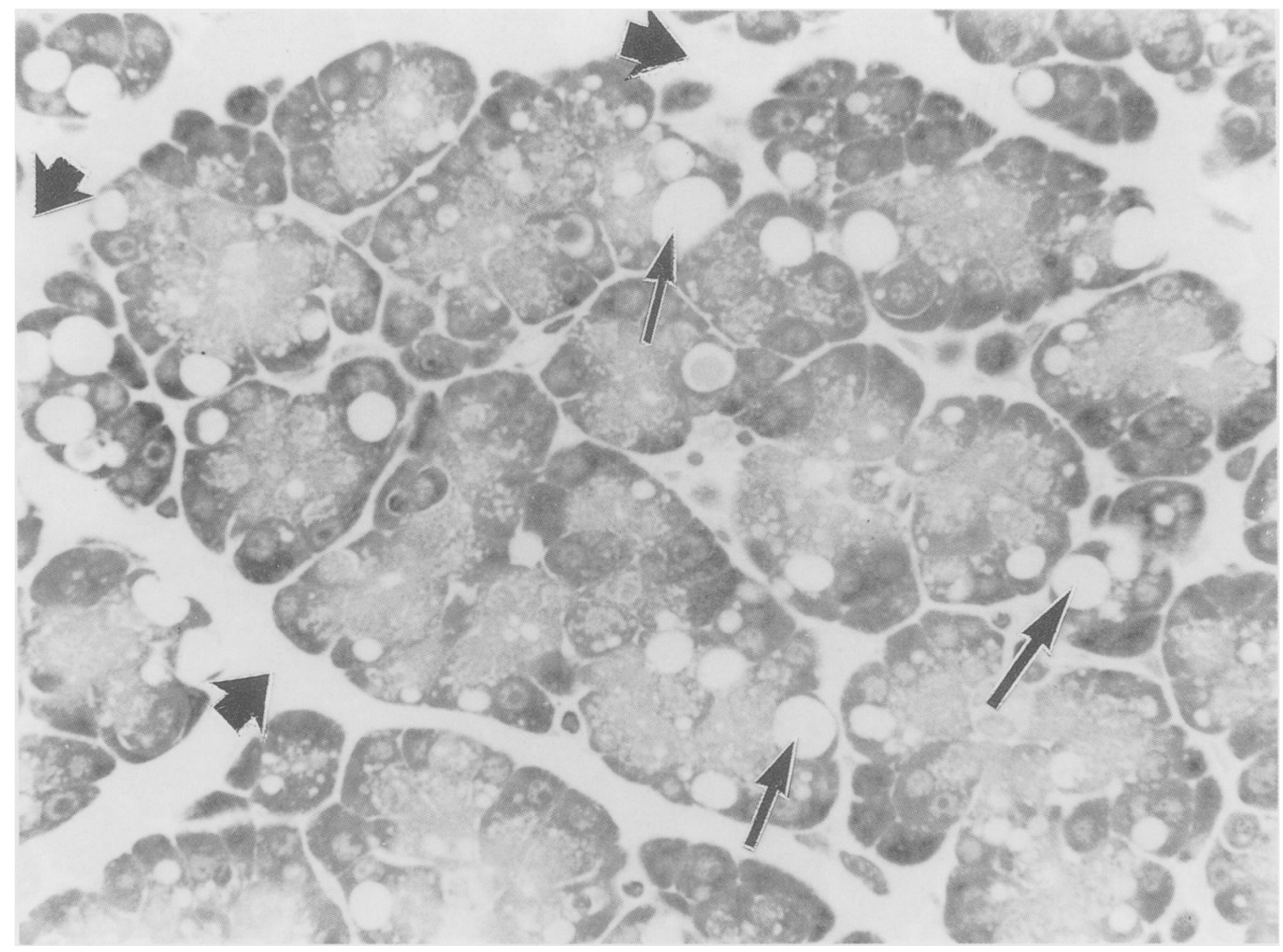

Fig. 1 Representative high power $(600 \times)$ photomicrograph of the pancreas from a rat at six hours after an initial three hour iv infusion of $C R(7.5 \mu \mathrm{g} / \mathrm{kg} / \mathrm{h})$ for induction of $A P$. This magnification is presented in order to illustrate the extensive acinar cell vacuolisation (arrows) characteristic of this form of $A P$ in rats not treated with PEG:SOD. Note that in numerous instances the vacuoles occupy the hasolateral portions of the acinar cells. A marked interstitial oedema is also present (large arrow heads).

\section{Results}

The pancreas weights and serum amylase concentrations in rats are given in Table 1 . The three hour iv infusion of group 2 rats with CR alone resulted in an approximate $27 \%$ increase in pancreas weight $(\mathrm{p}<0.005)$ and an eight-fold increase in serum amylase concentrations $(p<0 \cdot(001)$ compared with values obtained in control rats (group 1, infused with saline only) at the end of the six hour experiment. The six hour pancreas weights and serum amylase concentrations in groups 3,4 , and 5 rats given a single ip injection of varying concentrations of PEG:SOD immediately before the three hour CR infusion for AP induction were also significantly raised over control values and did not differ significantly from values obtained in rats infused with $C R$ alone. An iv bolus injection of $40000 \mathrm{U} / \mathrm{kg}$ of PEG:SOD immediately before the iv infusion of CR (group 6) also failed to significantly reduce pancreas weights below group 2 values although serum amylase concentrations in the group 6 animals were significantly reduced by approximately $35 \%(p<0 \cdot 05)$ compared with values in group 2 rats given $C R$ alone. In group 7 rats iv infused for three hours with CR $+40000 \mathrm{U} / \mathrm{kg} / \mathrm{h}$ of PEG:SOD followed by a further three hour infusion of PEG:SOD $(40000 \mathrm{U} / \mathrm{kg} / \mathrm{h})$ the six hour pancreas weights were significantly reduced by $25 \%(\mathrm{p}<0.001)$ compared with group 2 rats given CR alone and were also statistically indistinguishable from pancreas weights in control animals (group 1, infused with saline alone). Similarly, serum amylase concentrations in group 7 animals were significantly reduced $(\mathrm{p}<0.05)$ by approximately $35 \%$ compared with rats infused with CR alone (Table 1).

The pancreas weights and serum amylase concentrations in group 8 rats iv infused for six hours with CR+PEG:BSA $(13.8 \mathrm{mg}$ protein $/ \mathrm{kg} / \mathrm{h})$ were 


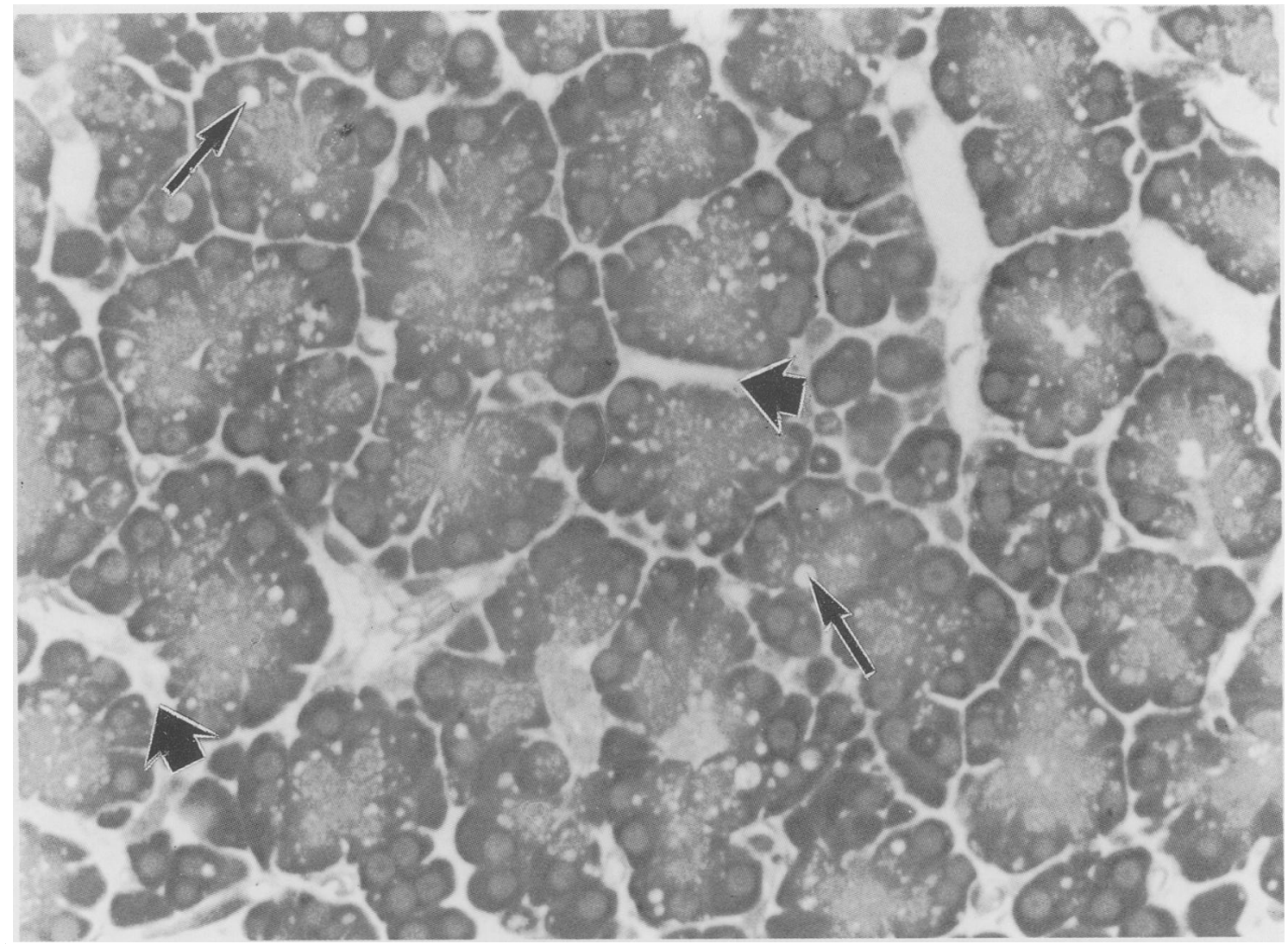

Fig. 2 Representative high power $(600 \times)$ photomicrograph of the pancreas from a rat at six hours that was initially iv infused for three hours with a combination of CR $(7 \cdot 5 \mu \mathrm{g} / \mathrm{kg} / \mathrm{h})+P E G: S O D(40000 \mathrm{U} / \mathrm{kg} / \mathrm{h})$ followed by a three hour iv infusion of PEG:SOD (40000 U/kg/h) alone. While acinar cell vacuolisation is evident (arrows), the extent of vacuolisation was significantly lower than that observed in rats with AP not treated with PEG:SOD (see Fig. I above and Table 2). The vacuoles that are present also appear to be reduced in size compared with rats with AP not treated with PEG:SOD although a quantitative, morphometric analysis of this phenomenon was not undertaken in the present study. The extent of interstitial oedema is reduced (large arrow heads) and acinar cell congestion is lessened compared with the pancreas in rats with AP not treated with PEG:SOD (compared with Fig. 1, above) consistent with the findings of a significant reduction in pancreas weights in PEG:SOD treated rats (see Table 1).

statistically indistinguishable from values observed in group 2 rats treated with CR alone (Table 1).

The histological grading of pancreas specimens is presented in Table 2. The most prominent histological features of the pancreas of rats infused with $\mathrm{CR}$ alone for induction of AP were a marked interstitial oedema (evidenced by the significant pancreas weight gains over control rat values - see Table 1), extensive acinar cell vacuolisation, minor evidence of inflammatory changes and minimal or no evidence of cell necrosis (Table 2). Pancreas histology in rats ip injected with either varying doses of PEG:SOD (groups 3, 4, and 5) or with an iv bolus of PEG:SOD (group 6) was indistinguishable from rats given $C R$ alone (Table 2). Similarly, pancreas histology in rats with $C R$ induced $A P$ that were iv infused with PEG:BSA (group 8) for six hours at a protein concentration equivalent to the six hour iv infusion dose of PEG:SOD was also indistinguishable from rats infused with $\mathrm{CR}$ alone. By contrast, the pancreas of rats which received a continuous six hour iv infusion of PEG:SOD in addition to the initial three hour infusion of CR (group 7) showed much less oedema and a significant reduction $\mathrm{p}<0.01$ in acinar cell vacuolisation compared with rats treated with CR alone (Table 2). 


\section{Discussion}

We have shown in the present study that a continuous iv infusion of $40000 \mathrm{U}$ PEG:SOD/ $\mathrm{kg} / \mathrm{h}$ for six hours in conscious rats significantly protects the pancreas from development of AP (as judged by reductions in pancreas weight gains, serum amylase concentrations, and pancreas histopathology) produced by supramaximal stimulation of the pancreas with CR. By contrast, in rats iv infused in an identical fashion with PEG:BSA for six hours at a protein concentration equivalent to that in rats infused with PEG: SOD, no protection against CR induced AP was observed. This latter result suggests that the beneficial effects of PEG:SOD in CR induced AP are specific to the enzyme and not related to possible non-specific effects of either the PEG or protein load infused.

The only known biological action of SOD is the catalytic dismutation of potentially cytotoxic superoxide anions $\left(\mathrm{O}_{2}^{-}\right)$to hydrogen peroxide $\left(\mathrm{H}_{2} \mathrm{O}_{2}\right)$ and $\mathrm{O}_{2}{ }^{783031}$ While $\mathrm{H}_{2} \mathrm{O}_{2}$ is also potentially cytotoxic, intracellular enzymes such as catalase and glutathione peroxidase catabolise this compound to $\mathrm{H}_{2} \mathrm{O} .{ }^{6-830}$ It would thus appear from our findings that at least one contributory process involved in the in vivo pathogenesis of CR-induced AP is the generation of oxygen-derived free radical species.

Interestingly, prior work by Sanfey et al have shown that oxygen derived free radicals are involved in the early pathogenesis of AP in ex vivo, canine pancreas models of the disease. ${ }^{910}$ In this latter work perfusion of the pancreas with a combination of exogenous SOD and catalase significantly suppressed weight gains and hyperamylaesaemia in the free fatty acid and duct obstruction models of AP and perfusion with SOD alone was effective in attenuating AP induced by ischaemia. ${ }^{910}$ In the present study we did not examine the effects of catalase (alone or in combination with PEG:SOD) on CR-induced AP. The present findings together with the work of Sanfey et $a l^{910}$ using a different species and markedly different modes of AP induction suggest that the generation of oxygen derived free radicals are an important mechanism in the pathogenesis of AP induced by widely diverse stimuli. These compounds (which are highly reactive oxidising and reducing agents that may damage cells by peroxidation of structural cell membrane lipids, degradation of extracellular collagen and hyaluronic acid, perturbation of lysosomal and mitochondrial membranes, and by direct damage to nucleic acids and proteins ${ }^{7830}$ have also been implicated in pathogenetic processes in diverse tissues such as the intestine, stomach, kidney, and heart. ${ }^{671-33}$

In the present work single ip or iv bolus injections of PEG:SOD at doses up to $40000 \mathrm{U} / \mathrm{kg}$ failed to attenuate CR induced AP whereas a continuous iv infusion of $40000 \mathrm{U}$ PEG:SOD for six hours was effective. These data suggest the results are attributable to the effective dose of PEG:SOD delivered because in group 7 rats (continuously iv infused with PEG:SOD) a total dose of $240000 \mathrm{U} / \mathrm{kg}$ was administered during the six hour experiment.

In previous studies (unpublished observations) we were unable to show a protective effect of administration of native SOD on CR-induced AP in rats despite the fact that the dosages of native SOD used were two to three-fold higher than dosages of PEG:SOD used in the present study. We attribute this lack of an effect of native SOD to its extremely short circulating half life in the rat compared with PEG:SOD $(<$ six minutes and $>35 \mathrm{~h}$, respectively). ${ }^{27}$ It should be pointed out that the work of Sanfey et a $l^{910}$ in which high dose, native SOD protected the ex vivo canine pancreas from AP, a small volume, closed loop perfusate was used which may have decreased the rate of clearance of SOD from the perfusate and, thus, effectively prolonged the circulating half life of the compound. Interestingly, a number of studies which have evaluated the effects of SOD on other inflammatory processes in the rat - for example reverse passive Arthus reaction, carrageenan induced foot oedema, immune complex glomerulonephritis, have also shown that exogenously administered, native SOD is virtually without effect whereas SOD derivatised to either Ficoll (which extends the circulating half life of SOD) or PEG evokes significant reductions in the inflammatory processes. ${ }^{27}$

During the time the present work was in progress Guice et al reported that in rats a single iv bolus dose of a combination of native SOD and catalase given 30 minutes after a 12 hour continuous iv infusion of CR for induction of AP resulted in a significant reduction of pancreas weights and an improvement in pancreas histopathology at 24 hours compared with animals given CR alone.$^{13}$ Acceptance of this work, however, is made difficult by two major points. First, AP was actually worsened in the Guice et al study when rats were pretreated with SOD+catalase 30 minutes before the beginning of the CR infusions. ${ }^{13}$ Second, only one injection of the free radical scavenging enzymes was administered in their studies which encompassed a 24 hour period. ${ }^{13}$ Because of the short circulating half life (minutes) of native SOD as well as catalase, ${ }^{2734}$ it is difficult to envision how such short term enzyme actions could have such profound effects over a 24 hour experimental period, especially when the beneficial effects were elicited at a time when severe pancreatic damage had already been achieved by a 12 hour CR infusion. 
More recently, Saluja and coworkers reported in abstract form ${ }^{35}$ that an iv pre-infusion of rats with $130000 \mathrm{U}$ native SOD/ $\mathrm{kg} / \mathrm{h}$ for one and a half hours followed by a three and a half hour infusion of SOD + CR significantly reduced pancreatic weight gains but not the increases in serum amylase resulting from CR-induced AP. Our previous results (unpublished observations) using native SOD at doses approximating those used by Saluja et al ${ }^{35}$ also indicate that hyperamylaesaemia is not attenuated by native SOD in CR-induced AP although we failed to confirm their observations that pancreas weights are significantly reduced by native SOD in this animal model.

The source of oxygen derived free radicals in CR induced AP in rats is not clear, although previous studies by Sanfey et al on isolated, perfused canine pancreas models of $\mathrm{AP}^{36}$ and more recently by us in rats with $\mathrm{CR}$ induced $\mathrm{AP}^{37}$ have shown that allopurinol, a xanthine oxidase inhibitor, significantly attenuates pancreatic oedema and hyperamylaesaemia occurring during the early pathogenetic process. Additionally, Rutledge and coworkers have shown that allopurinol also significantly reduces peripancreatic oedema in mice with a lethal, acute haemorrhagic pancreatitis induced by feeding a CDE diet. ${ }^{\text {1 }}$ Allopurinol did not, however, reduce either the magnitude of hyperamylaesaemia, pancreatic necrosis, or mortality rates of mice in these latter studies. ${ }^{.1}$

While the above findings are consistent with at least a partial involvement of xanthine oxidase (an enzyme derived from intracellular enzymatic conversion of xanthine dehydrogenase and responsible for reduction of molecular oxygen to superoxide anion) in the pathogenesis of AP in diverse animal models of the disease, Devenyi et al were unable to detect pancreatic xanthine oxidase activity in mice with CR induced AP and allopurinol also failed to alter pancreatic oedema and hyperamylaesaemia in this animal model of the disease. ${ }^{12}$ These findings contrast with our previous observations that allopurinol attenuates CR induced AP in rats ${ }^{37}$ and the results of the present study indicating that oxygen derived free radicals are involved in the disease process. The differences between the work of Devenyi et al ${ }^{12}$ and our studies may be the result of species differences or differences in doses and duration of allopurinol therapy. Clearly, more research is required to identify the source and role of oxygen derived free radicals in AP.

It is not clear in the present work whether the protective effects of exogenous PEG:SOD on CR induced AP are caused by the enzyme acting intracellularly or extracellularly on the pancreas. It is known, however, that compounds such as $\mathrm{O}_{2}^{-}$and $\mathrm{H}_{2} \mathrm{O}_{2}$ can pass through cell membranes by either diffusional processes or by transport through anionic membrane channels ${ }^{8}$ suggesting that exogenous PEG:SOD in our studies could be acting extracellularly through catalytic inactivation of superoxide anion diffusing into the interstitium from acinar cells. The enzyme could also be acting extracellularly by inactivating oxygen derived free radicals produced by complement activated neutrophils ${ }^{8}$ or by scavenging oxygen derived free radicals in the interstitium that generate chemotactic factors for neutrophils ${ }^{8}$ and, thereby, prevent leucocyte infiltration into the pancreas. We have shown recently that complement system activation does occur in a CR induced AP model in rats ${ }^{38}$ and a role for neutrophils in the pathogenesis of AP is clearly an area warranting further research.

Because of the prolonged half life of PEG:SOD we believe that a high dose of this compound infused iv over one hour could result in longterm amelioration of CR induced AP. At this time, however, limited availability of PEG:SOD has not allowed extension of the present studies.

We thank Mrs Ruth McLaughlin for expert technical assistance. We also thank Dr F Davis (Enzon, Inc) for the gift of the PEG:SOD and PEG:BSA used in these studies. This work was supported in part by a NIH grant (AM3422-03) to IGR and JRW.

\section{References}

1 Renner IG, Savage WT, Pantoja JL, Renner VJ. Death due to acute pancreatitis: a retrospective analysis of 405 autopsy cases. Dig Dis Sci 1985; 30: 1005-18.

2 Steer ML. Etiology and pathophysiology of acute pancreatitis. In: Go VLW, Brooks FP, DiMagno EP, Gardner JD, Lebenthal E, Scheele GA, eds. The exocrine pancreas: biology, pathobiology, and diseases. New York: Raven Press, 1986: 465-74.

3 Thompson AG. Proteinase inhibitors in experimental and clinical pancreatitis. Ann NY Acad Sci 1968: 146: 540-7.

4 Scheele GA. Biochemical concepts and markers in acute pancreatitis. In: Gyr K, Singer M, Sarles H, eds. Pancreatitis: concepts and classification. Amsterdam: Elsevier, 1984: 19-25.

5 Adler G, Kern HF, Scheele GA. Experimental models and concepts in acute pancreatitis. In: Go VLW, Brooks FP, DiMagno EP, Gardner JD, Lebenthal E, Scheele GA, eds. The exocrine pancreas: biology, pathobiology, and diseases. New York: Raven Press, 1986: 407-21.

6 McCord JM, Roy RS. The pathophysiology of superoxide: roles in inflammation and ischemia. Can $J$ Biochem Physiol Pharmacol 1982; 60: 1346-52.

7 Slater TF. Free radical mechanisms in tissue injury. Biochem J 1984; 222: 1-15.

8 Fantone JC, Ward PA. Oxygen-derived free radicals and their metabolites: relationship to tissue injury. Curr 
Concepts Kalamazoo, Mich: The Upjohn Co, 1985: 451.

9 Sanfey H, Bulkley GB, Cameron JB. The role of oxygen-derived free radicals in the pathogenesis of acute pancreatitis. Ann Surg 1984; 200: 405-513.

10 Sanfey H, Sarr MG, Bulkley GB, Cameron JL. Oxygenderived free radicals and acute pancreatitis: a review. Acta Physiol Scand [suppl] 1986; 548: 109-18.

11 Rutledge PL, Saluja AK, Powers RE, Steer ML. Role of oxygen-derived free radicals in diet-induced hemorrhagic pancreatitis in mice. Gastroenterology 1987; 93: 41-7.

12 Devenyi ZJ, Orchard JL, Powers RE. Xanthine oxidase activity in mouse pancreas: effects of caerulein-induced acute pancreatitis. Biochem Biophys Res Commun 1987; 149: 841-5.

13 Guice KS, Miller DE, Oldham KT, Townsend CM, Thompson JC. Superoxide dismutase and catalase: a possible role in established pancreatitis. Am J Surg 1986; 151: 163-9.

14 Lampel M, Kern HF. Acute interstitial pancreatitis in the rat induced by excessive doses of a pancreatic secretagogue. Virchows Arch [A] 1977; 373: 97-117.

15 Adler G, Hupp T, Kern HF. Course and spontaneous regression of acute pancreatitis in the rat. Virchows Arch [A] 1979; 382: 32-47.

16 Watanabe O, Baccino FM, Steer ML, Meldolesi J. Effects of supramaximal caerulein stimulation on the ultrastructure of the rat pancreatic acinar cell: early morphological changes during the development of experimental pancreatitis. Am J Physiol 1984; 246: G457-67.

17 Adler G, Rohr G, Kern HF. Alteration of membrane fusion as a cause of acute pancreatitis in rats. Dig Dis Sci 1982; 27: 983-1002.

18 Renner IG, Wisner JR Jr, Rinderhnecht H. Protective effects of exogenous secretin on ceruletide-induced acute pancreatitis in rats. J Clin Invest 1983; 72: 108192.

19 Steer ML, Meldolesi J, Figarella C. Pancreatitis: the role of Lysosomes. Dig Dis Sci 1984; 29: 934-8.

20 Niederau C, Ferrell LD, Grendell JH. Caeruleininduced acute necrotizing pancreatitis in mice: protective effects of proglumide, benzotript and secretin. Gastroenterology 1985; 88: 1192-204.

21 Renner IG, Wisner JR Jr, Lavigne BC. Partial restoration of pancreatic function by exogenous secretin in rats with ceruletide-induced acute pancreatitis. Dig Dis Sci 1986; 31: 305-13.

22 Renner IG, Wisner JR Jr. Ceruletide-induced acute pancreatitis in the dog and its amelioration by exogenous secretin. Int J Pancreatol 1986; 1: 39-49.
23 Wisner JR Jr, Renner IG, Grendell JH. Niederau C, Ferrell LD. Gabexate mesilate (FOY) protects against ceruletide-induced acute pancreatitis in the rat. Pancreas 1987; 2: 181-6.

24 Pyatak PS, Abuchowski A. Davis FF. Preparation of a polyethylene glycol: superoxide dismutase adduct, and an examination of its blood circulating life and antiinflammatory activity. Res Comm Chem Pathol Pharmacol 1980; 29: 117-27.

25 Boccu E, Velo GP, Veronese FM. Pharmacokinetic properties of polyethylene glycol derivatized superoxide dismutase. Pharmacol Res Commun 1982; 14: 113-20.

26 Veronese FM, Boccu E, Schiavon O, et al. Antiinflammatory and pharmacokinetic properties of superoxide dismutase derivatized with polyethylene glycol via active esters. J Pharm Pharmacol 1983; 35: 757-8.

27 McCord JM, English D. Superoxide dismutase: an antiinflammatory drug. In: Holcenberg JS, Roberts J, eds. Enzymes as drugs. New York: John Wiley, 1981: 35365 .

28 Adler HL, Rocssler EB. Introduction to probability and statistics. San Francisco: WH Freeman, 1968.

29 Steele RGD, Torie JH. Principles and procedures of statistics. New York: McGraw-Hill, 1960.

30 McCord JM. The superoxide free radical: its biochemistry and pathophysiology. Surgery 1983; 94: 412-4.

31 Proctor $\mathrm{PH}$, Reynolds ES. Free radicals and disease in man. Physiol Chem Phys Med NMR 1984; 16: 175-95.

32 Parks DA, Bulkley GB, Granger DN. Role of oxygenderived free radicals in digestive tract diseases. Surgery 1983; 94: 415-22.

33 Parks DA, Bulkley GB, Granger DN. Role of free radicals in shock, ischemia, and organ preservation. Surgery 1983; 94: 428-32.

34 Abuchowski A, McCoy JR, Palczuk NC, Van Es T, Davis FF. Effect of covalent attachment of polyethylene glycol on immunogenicity and circulating life of bovine liver catalase. J Biol Chem 1977; 252: 3582-6.

35 Saluja A, Powers RE, Saluja M, Rutledge P, Steer ML. The role of oxygen-derived free radicals in caeruleininduced pancreatitis. Gastroenterology 1986; 90: 1613.

36 Sanfey H, Bulkley GB, Cameron JL. The pathogenesis of acute pancreatitis. The source and role of oxygenderived free radicals in three different experimental models. Ann Surg 1985; 20: 633-9.

37 Wisner JR Jr, Renner IG. Allopurinol attenuates caerulein-induced acute pancreatitis in the rat. Gut 1988; 29: 926-9.

38 Wisner JR Jr, Renner IG, Glovsky M. Complement activation in an animal model of acute pancreatitis [Abstract]. Clin Res 1985; 33: 40A. 